\title{
Editorial
}

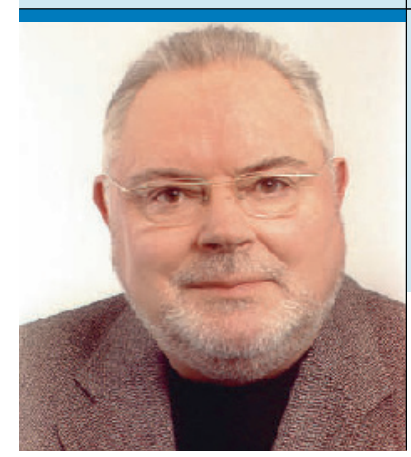

"Die Hoffnung hat sich nicht erfüllt. In der KBV bleibt nun alles bei den alten eingefahrenen Strukturen."

Dr. med. Dieter Leithäuser,

Chefredakteur und niedergelassener HNO-Arzt, Warburg

\section{Verkrustete Strukturen siegen - wieder einmal?}

U nser Kollege Dirk Heinrich, 1. Vorsitzender des HNO-Berufsverbands, hat sich leider vergeblich bemüht, der KBV eine neue, erfolgreichere Marschrichtung zu geben. Schade, eine Verbesserung unserer Situation ist nun auch weiterhin nicht zu erwarten. Es bleibt alles unter dem Einfluss der bekannten Seilschaften beim Alten. Köhler und sein Gefolge haben die Hartnäckigkeit von festgefahrenen Verkrustungen einmal mehr vorgeführt. Immerhin zeigen die 19 Stimmen für den HNO-Kollegen Heinrich, wie es hätte laufen können. Heinrich hat mit seinem 10-Punkte-Papier immerhin einen überzeugenden Plan zur „Reanimation der Selbstverwaltung“ vorgelegt.

Trotz Niederlage sollte aber unser fachärztliches Ziel weiter verfolgt werden. Gibt es Voraussetzungen dafür? Zitat Heinrich: Ja, ein klares Votum der Einheit. Einheit von Haus- und Fachärzten, Einheit der KVen, Anerkennung der Basis.

Mit der Headline „Plagiat oder Lüge?“"könnte man einen Vorgang aus der ehrwürdigen, von mir sonst geschätzten FAZ vom 28. Februar dieses Jahres beschreiben. Der Autor Andreas Mihm schreibt in seinem Artikel: „Gutachter halten Ärzteeinkommen für überzogen“: Die Zielgröße von 105.000 Euro sei weit überschritten. 164.000 Euro seien genug im System. Er zitiert dabei hauptsächlich eine Studie des IGESInstitutes in Berlin. Hier stand allerdings etwas völlig anderes zu lesen: „Keinesfalls stellt unsere Expertise die Behauptung auf, dass die gegenwärtigen Arzteinkommen überzogen“ seien. So manipuliert selbst die renommierte FAZ ihre Leser. Da freue ich mich doch über einen zu Guttenberg, der hat wenigstens nur abgeschrieben und nicht die Wahrheit um $180 \mathrm{Grad}$ verdreht wie Herr Mihm von der FAZ.

Übrigens kam gerade eine Eilmeldung herein: KT zu Guttenberg hat erklärt, dass er die Musik bei seinem Zapfenstreich „Smoke on the water" nicht selbst komponiert hat.

In diesem Sinne

Ihr

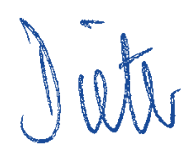

